

\title{
The Removal of Dye from Aqueous Solution by Adsorption on Low Cost Adsorbents
}

\author{
J. J. CHAMARGORE, J. V. BHARAD, B. R. MADJE and M. B. UBALE* \\ Post Graduate Department of Chemistry, \\ Vasantrao Naik Mahavidyalaya, Aurangabad-431 003 (M.S.), India. \\ mbubale@yahoo.com
}

Received 27 August 2009; Accepted 20 October 2009

\begin{abstract}
Removal of color from aqueous solution by using low cost easily available adsorbent was conducted by batch experiment. The potential of the low cost adsorbent (Marble powder - treated and untreated) to remove methylene red from aqueous solution were assessed at room temperature. Laboratory investigation of the potential of marble powder and sulphuric acid treated marble powder to remove dye color from aqueous solution has been studied. Parameters studied included $\mathrm{pH}$, adsorbent dose, initial dye concentration and contact time. The influence of these system variables were investigated to observe the effect on the rate of dye uptake. Sulphuric acid treated marble powder has shown better adsorptive capacity than untreated marble powder and thus it has become an interesting option for dye removal from industrial effluents.
\end{abstract}

Keywords: Azo dye, Methylene red, Sulphuric acid treated marble power (SATMP), Untreated marble powder (UTMP).

\section{Introduction}

Major pollutants in wastewaters from food processing, cosmetics paper, dye manufacturing, printing and textile are color left by dyes. Colored dye wastes frequently contains a spectrum of dye color may indicate the existence of toxicants. The discharge of dye bearing wastewater into natural stream or on land has created significant concern as the dye impact toxicity and impedes light penetration and thus upsets the biological activity ${ }^{1-3}$. In the last decade, water resources have been decreased because of global warming and limited water treatment methods are available such as filtration, oxidation, sedimentation and adsorption ${ }^{4-6}$. Among these treatment methods adsorption of pollutants on low cost materials are the cheapest method. Recently, adsorption process has offered most economical and effective treatment method for removal of dyes ${ }^{7}$. Most conventional adsorption systems use activated carbon which is expensive and necessitates regeneration, so there was a search for low cost materials to remove organic contaminates such as dyes from industrial effluents ${ }^{8-9}$. Literature survey reveals that there has been numerous works reported using low cost adsorbents for dye removal, which are economical viable, easily available, highly effective in adsorption process. 
The aim of the present study was to determine the optimum conditions for the removal of an azo dye i.e. methylene red from aqueous solution by adsorption technique using sulphuric acid treated marble powder (SATMP) and untreated marble powder (UTMP) also to show the comparative adsorptive capacities of SATMP and UTMP for azo dyes.

\section{Experimental}

Now a day there is numerous numbers of low cost commercially available adsorbents which has been used for the dye removal (Table 1). So many adsorbents are more economical easily available.

Table 1. Comparison for adsorption of some dyes on various adsorbents.

\begin{tabular}{cll}
\hline S. No. & \multicolumn{1}{c}{ Adsorbents } & \multicolumn{1}{c}{ Dye(s) } \\
\hline 1 & Duckweed & Methylene blue $^{9}$ \\
2 & Sewage Sludge & Basic red $^{10}$ \\
3 & Waste Newspaper & Basic Blue $^{11}$ \\
4 & Rice Husk & Malachite Green $^{12}$ Acid $^{14}$ \\
5 & Sugarcane bagasse & yellow $^{13}$ Acid blue $^{14}$ \\
6 & Coir Pid orange & Congo red $^{15}$ \\
7 & Straw & Basic lue $^{17}$ \\
8 & Treated sawdust & Methylene blue $^{18}$ \\
9 & Neem leaf powder & Congo red $^{19}$ \\
10 & Banana peel & Congo red $^{20}$ \\
11 & Bagasse fly ash & Congo red $^{21}$ \\
12 & Mahua oil cake & Congo red $^{22}$ \\
\hline
\end{tabular}

\section{Preparation of adsorbents}

The adsorbent material (marble powder) were collected and washed with distill water to remove dirt, impurities and then for acid treatment it was mixed with concentrated sulphuric acid $(1: 2 \mathrm{v} / \mathrm{w})$ and left to dry at room temperature for $24 \mathrm{~h}$. The dried material (sample) was then kept in oven for $24 \mathrm{~h}$ at $180{ }^{\circ} \mathrm{C}$ for activation and was allowed to cool at room temperature. The product so obtained from activation step were blended to produce granular activated adsorbent and washed with distill water to remove excess acid. The $\mathrm{pH}$ of it becomes constant and the filtrations during washing were carried by vacuum filtered through whatman filter paper. The product obtained was wet-screed and dried in oven at $80{ }^{\circ} \mathrm{C}$ overnight.

\section{Preparation of dye solution}

For the present study adsorbate methylene red was procured from the local supplier. The characteristics of methylene red are enlisted in Table 2. An accurately weighed quantity of methylene red $(0.5635 \mathrm{~g})$ was dissolved in distilled water to prepare the stock solution $(500 \mathrm{mg} / \mathrm{L})$. The stock solution was then properly wrapped with aluminum foil and stored in a dark place to prevent direct sunlight, which may cause decolourisation. Experimental solutions of the desired concentrations were obtained by successive dilutions. Dye concentrations were determined by using absorbance values measured before and after the treatment at $617 \mathrm{~nm}$ with shimadzu UV visible spectrophotometer (model UV mini 1240). Experiments were carried out at initial pH values ranging from 2 to 9 . Initial $\mathrm{pH}$ was controlled by addition of sodium hydroxide $(\mathrm{NaOH})$ or hydrochloric acid $(\mathrm{HCl})$ 
Table 2. Characteristic of the methylene red.

\begin{tabular}{ll}
\hline Chemical Formula & $\mathrm{C}_{15} \mathrm{H}_{15} \mathrm{~N}_{3} \mathrm{O}_{2}$ \\
\hline Molecular Weight & 269.31 \\
Melting Point & $179-182{ }^{\circ} \mathrm{C}$ \\
Dye Content & $95 \%$ \\
Adsorption Max pH 4.5 & $523-526 \mathrm{~nm}$ \\
Adsorption Max pH 6.2 & $430-434 \mathrm{~nm}$ \\
Absorptivity (1\%, 1 cm pH 4.5) & $>1330$ \\
Absorptive (1\% 1 cm pH 6.2) & $>700$ \\
Transition Range & $\mathrm{pH} 4.2-6.2$ (Red Yellow) \\
\hline
\end{tabular}

\section{Adsorption experiments}

In each adsorption experiment, $100 \mathrm{~mL}$ of dye solution of known concentration and $\mathrm{pH}$ was added to $1 \mathrm{~g}$ of adsorbents in $250 \mathrm{~mL}$ round bottom flask at room temperature $\left(27 \pm 1^{\circ} \mathrm{C}\right)$ and the mixture were stirred on a rotary orbital shaker at $160 \mathrm{rpm}$ the initial $\mathrm{pH}$ of the mixture were varied between 2-8 this was controlled by the addition of dilute hydrochloric acid or sodium hydroxide solution. The experiments were carried by varying the amount of adsorbents ( 1 to $5.0 \mathrm{~g} / 100 \mathrm{~mL}$ ), concentration of dye solution $\left(50-250 \mathrm{mgL}^{-1}\right)$ and $\mathrm{pH}(2$ to 8$)$ at different time intervals.

\section{Results and Discussion}

\section{Effect of initial dye concentration}

The influence of the initial concentration of methylene red on the rate of adsorption onto the surface of SATMP and UTMP adsorbent was studied. The experiments were carried at fixed adsorbent dose $(1 \mathrm{~g} / 100 \mathrm{~mL})$ in the test solution at $\left(27 \pm 1{ }^{0} \mathrm{C}\right)$ room temperature, $\mathrm{pH}=7.0$ and at different initial concentrations of methylene red $(50,100,150,200$ and $250 \mathrm{mg} / \mathrm{L})$ and for different time intervals $(10,20,30,40,50$ and 60 minutes). The results obtained are presented in Table 3. It is evident that the percent adsorption efficiency of SATMP and UTMP decreased with the increase in the initial concentration in the solution. However for SATMP and UTMP equilibrium attainment was achieved only after 40 and 50 minutes. It may be attributed to the fact that SATMP have macro and microspores resulting in longer contact time between the dye molecule and the adsorbent.

Table 3. Effect of methylene red concentration on the dye adsorption.

\begin{tabular}{cccccccc}
\hline Initial dye & \multicolumn{7}{c}{ Percent dye removal with time, min } \\
\cline { 2 - 7 } concentration, mg/L & 10 & 20 & 30 & 40 & 50 & 60 \\
\hline \multicolumn{7}{c}{ Sulphuric acid treated marble powder } \\
50 & 82.3 & 82.5 & 82.7 & 83.2 & 84.0 & 85.8 \\
100 & 81.2 & 80.5 & 80.6 & 82.1 & 83.4 & 83.9 \\
150 & 79.4 & 79.2 & 79.0 & 80.0 & 80.6 & 80.9 \\
200 & 72.4 & 74.0 & 74.0 & 77.7 & 78.5 & 78.6 \\
250 & 65.1 & 68.4 & 69.2 & 72.0 & 75.0 & 77.2 \\
50 & Untreated marble powder \\
100 & 40.0 & 42.4 & 46.6 & 47.8 & 48.0 & 49.1 \\
150 & 35.5 & 39.6 & 42.4 & 40.3 & 41.3 & 41.7 \\
200 & 32.2 & 36.2 & 40.4 & 38.2 & 40.2 & 40.6 \\
250 & 26.8 & 29.4 & 33.2 & 31.0 & 31.8 & 32.9 \\
& 21.3 & 22.7 & 25.1 & 29.4 & 30.8 & 30.8 \\
\hline
\end{tabular}


In the process of dye adsorption initially dye molecules have to encounter the layer effect before diffusing from boundary layer film onto adsorbent surface. This is followed by the diffusion of dye into the porous structure of the adsorbent and takes relatively longer contact time. The time profile of dye uptake is a single smooth and continuous curve leading to saturation, suggesting the possible monolayer converge of dye on the surface of the adsorbent ${ }^{23}$. The efficiency of dye removal was increased as the agitation time increased and lowers initial dye concentration ${ }^{24}$.

\section{The effect of adsorbent dose}

The adsorption of methylene red on SATMP was studied by changing the quantity of adsorbent $(1,2,3,4$ and $5 \mathrm{~g} / 100 \mathrm{~mL})$ in the solution while keeping the initial dye concentration $(250 \mathrm{mg} / \mathrm{L})$ temperature $\left(27 \pm 1{ }^{\circ} \mathrm{C}\right)$ and $\mathrm{pH}(7.0)$ constant. Experiments were carried out at different contact times for 60 minutes as shown in Table 4 . The percent adsorption increased and equilibrium time decreased with increasing adsorbent doses. The adsorption increased from 59.0 to $95.1 \%$ as the sulphuric acid treated dose increased from $1 \mathrm{~g}$ to $5 \mathrm{~g} / 100 \mathrm{~mL}$ at equilibrium time (60 min.) for UTMP adsorption increased from 21.9 to $56.4 \%$ as the adsorbent dose increased from 1 to $5 \mathrm{~g} / 100 \mathrm{~mL}$ maximum dye removal was achieved within 50 to $60 \mathrm{~min}$. after which methylene red concentration in the test solution was almost constant increase in the adsorption with adsorbent dose can be attributed to the increase in adsorbent surface area and availability of more adsorption sites. The number of available adsorption sites increases by increasing the adsorbent dose.

Table 4. Effect of adsorbent dose on the dye adsorption.

\begin{tabular}{ccccccc}
\hline Adsorbent amount in & \multicolumn{7}{c}{ Percent dye removal with time, min } \\
\cline { 2 - 7 } $\mathrm{g}$ & \multicolumn{7}{c}{20} & 30 & 40 & 50 & 60 \\
\hline 1 & Sulphuric acid treated marble powder \\
2 & 35.2 & 39.5 & 45.4 & 49.5 & 54.7 & 59.0 \\
3 & 53.3 & 62.4 & 68.0 & 69.4 & 74.8 & 75.4 \\
4 & 73.5 & 77.3 & 70.7 & 80.6 & 80.6 & 86.0 \\
5 & 87.9 & 90.9 & 81.5 & 91.5 & 90.8 & 93.2 \\
1 & 90.4 & 92.2 & 82.4 & 917 & 91.2 & 95.1 \\
2 & Untreated marble powder & & \\
3 & 17.1 & 18.8 & 19.3 & 20.5 & 21.4 & 21.9 \\
4 & 24.3 & 25.4 & 27.2 & 28.3 & 29.6 & 30.2 \\
5 & 29.0 & 30.4 & 32.3 & 33.4 & 34.7 & 35.0 \\
& 38.4 & 40.2 & 42.0 & 43.4 & 44.5 & 45.3 \\
& 48.6 & 49.8 & 51.6 & 54.3 & 55.2 & 56.4 \\
\hline
\end{tabular}

\section{Effect of $p H$}

In order to study the effect of $\mathrm{pH}$ on methylene red adsorption on sulphuric acid treated marble powder experiments were carried out at $250 \mathrm{mg} / \mathrm{L}$ initial dye concentration with $1 \mathrm{~g} / 100 \mathrm{~mL}$ adsorbent mass at room temp $\left(27 \pm 1^{0} \mathrm{C}\right)$ for $2 \mathrm{~h}$ equilibrium time results are shown in Figure 1 . In case of untreated marble powder maximum dye removal of $50 \%$ was recorded at $\mathrm{pH} 8$. Between $\mathrm{pH}$ range of 2-6 the percentage of dye was nearly equal $48 \%$ significant increase in dye removal efficiency for sulphuric acid treated marble powder (STAMP) when compared with untreated marble powder (UTMP) it was not significantly affected by $\mathrm{pH}$. Thus not favoring the adsorption of the positively charge dyes cation ${ }^{25}$. There might be another mode of adsorption such as ion exchange. As the $\mathrm{pH}$ value increased from 6 to 8 , the efficiency of the dyes removal is slightly become lesser. The dye adsorption by SATMP was (67-82\%) in the studied pH range and untreated marble powder (UTMP) $(50 \%)$. The minimum percentage removal was recorded at $\mathrm{pH} 2$ is $42.31 \%$ the highest percentage recorded at $\mathrm{pH} 8$ is $83 \%$. 




\section{Conclusions}

Figure 1. Effect of $\mathrm{pH}$ on adsorption of methylene red.

The removal of methylene red from simulated waste water by using chemically treated marble powder with sulphuric acid under different experimental conditions shows that as the amount of the adsorbent was increased the percentage of dye removal. Higher adsorption percentages were observed at lower concentrations of methylene red SATMP showed a better perform compared to UTMP. This study had shown that UTMP had a lower adsorption efficiency compared to SATMP at any given $\mathrm{pH}$ value. Initial dyes concentration over a range of 2 to 6 decreased the efficiency of the dyes removal for both adsorbents. This study proved that treated marble powder is an attractive option for dye removal from dilute industrial effluents.

\section{References}

1. Ghosh S, Das S K, Guha A K and Sanyal A K, J Hazard Mater., 2009, 172(1), 485.

2. Caparkaya D and Cavas L, Acta Chim Slov., 2008, 55, 547.

3. Sharma P, Kaur A and Markenday D K, Indian J Environ Protect., 1999, 19(6), 442.

4. Aroguz A. Z, Gulen J and Evers R H, Bioresource Technol., 2009, 99,1503.

5. Garg V K, Amita M, Kumar R and Gupta R, Dyes and Pigments, 2004, 63, 243.

6. Tsai W T, Chang C Y, Ing C H and Chang C F, J Colloid Interface Sci ., 2004, 275, 72.

7. Vadivelan V and Vasanth Kumar K, J Colloid Interface Sci., 2005, 286, 90.

8. Mckay G, Porter J F and Prasad G R, Water Air Soil Pollution, 1999, 114, 423.

9. Inbaraj B S, Seivarani K and Sulochana, J Sci Ind Res., 2002, 61,971.

10. Waranusantigul P Pokethiti Y P and Upatham E S, Environ Poll, 2008, 125, 385.

11. Martin M J, Artola A, Balaguer D and Rigola M, Chem Engg J., 2003, 94, 231.

12. Okada K, Yamamoto N, Kameshima Y and Yasumori A, J Colloid Interface Sci., 2003, 263, 194.

13. Guo Y, Yang S, Fu W, Qi J, Li R. Wang Z and Xu H, Dyes and Pigments, 2003, 56, 219.

14. Malik P K, Dyes and Pigments, 2003, 56, 239.

15. Mohamed M M, J Colloid Interface Sci., 2004, 272, 28.

16. Tsai W T, Chang C Y, Lin M, Chien S F, Sun H F and Hsieh M, Chemosphere, 2001, 45, 51.

17. Namasivayam C and Kavita D, Dyes and pigments, 2002, 54, 47.

18. Kannan N and Sundaram M M, Dyes and pigments, 2007, 51, 25.

19. Bhttacharyya K G and Shrama J A, J Environ Manag, 2004, 71, 217.

20. Annaduari G, Juang R S and Lee D.J, J Hazard Mater., 2002, 92, 263.

21. Mall I D, Srivastava V C, Agarwal N K and Mishra I M, Chemospere, 2005, 61, 492.

22. Mishra S, Prakash D J and Ramakrishna G, EJEAFChe., 2009, 8(6), 425.

23. Glarg V K, Amita M, Kumar R and Gupta R, Dyes and Pigments, 2004, 63, 243.

24. Saiful Azhar S, Ghuniey Liew A, Suhardy D, Farizul Hafiz K and Irfan Hatim M D, Am J Appl Sci., 2005, 2(11),1499.

25. Namasivayam C, Dinesh Kumar M, Selvi Begam K, Ashrufffunissa R, Vanathi T and Yamuna R T, Biomass Bioenergy, 2001, 21, 477. 




International Journal of

Medicinal Chemistry

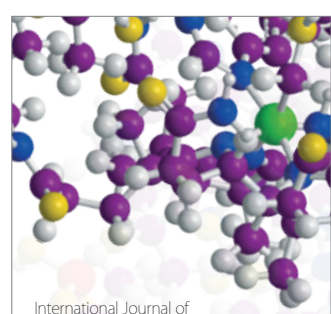

Carbohydrate Chemistry



The Scientific World Journal
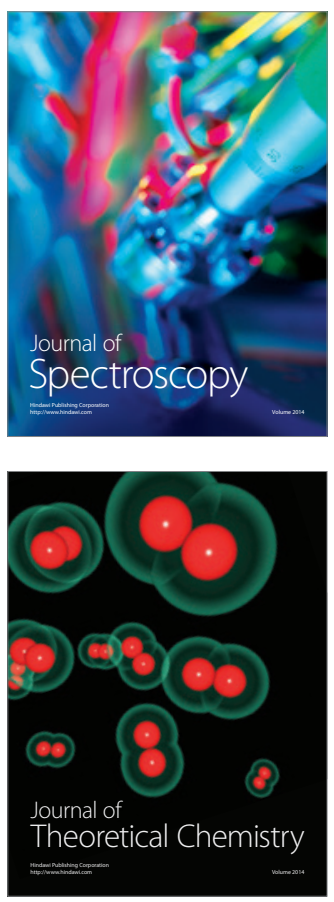


Submit your manuscripts at

http://www.hindawi.com
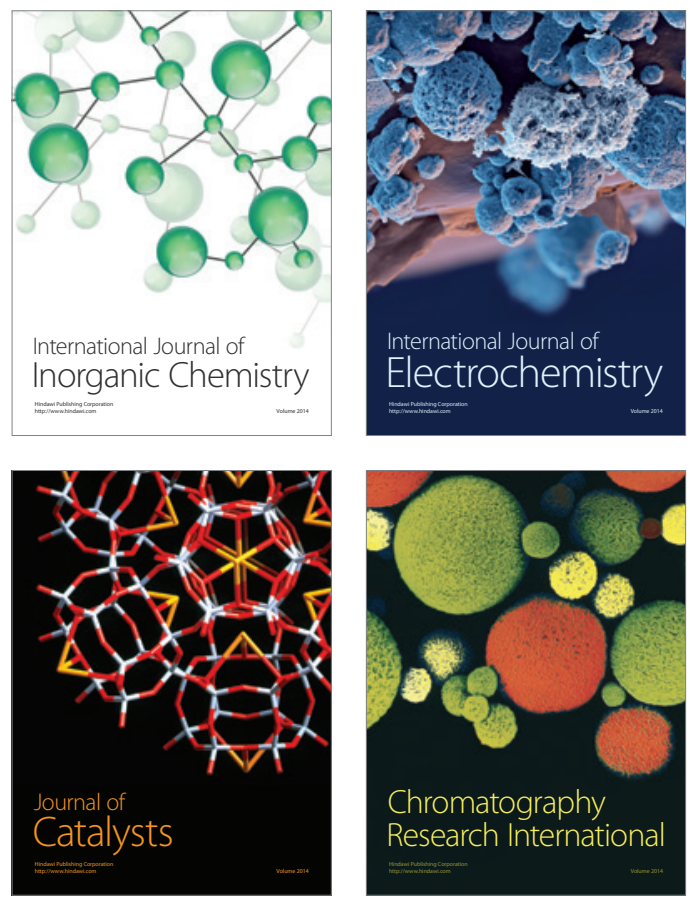
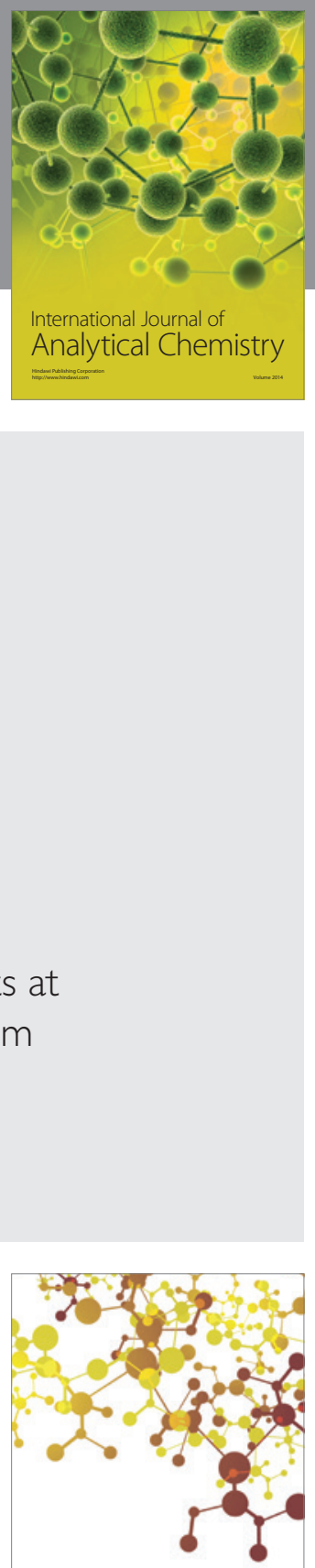

Journal of

Applied Chemistry
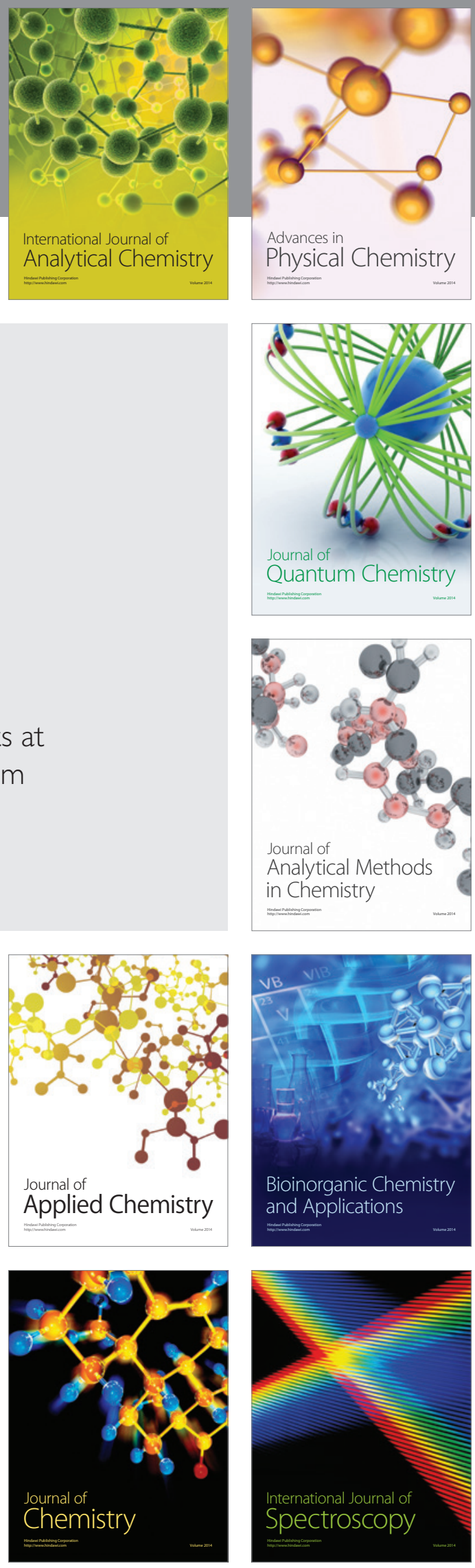